\title{
Observations and model calculations of an additional layer in the topside ionosphere above Fortaleza, Brazil
}

\author{
B. Jenkins ${ }^{* 1}$, G. J. Bailey ${ }^{1}$, M. A. Abdu ${ }^{2}$, I. S. Batista ${ }^{2}$, N. Balan ${ }^{3}$ \\ ${ }^{1}$ Upper Atmosphere Modelling Group, School of Mathematics and Statistics, University of Sheffield, Sheffield S3 7RH, UK \\ 2 Instituto Nacional de Pesquisas Espaciais, Caixa Postal 515, 12201-970, São José dos Campos, S.P., Brazil \\ ${ }^{3}$ Radio Atmospheric Science Center, Kyoto University, Uji, Kyoto 611, Japan
}

Received: 14 October 1996 / Revised: 31 January 1997 / Accepted: 5 February 1997

\begin{abstract}
Calculations using the Sheffield University plasmasphere ionosphere model have shown that under certain conditions an additional layer can form in the low latitude topside ionosphere. This layer (the F3 layer) has subsequently been observed in ionograms recorded at Fortaleza in Brazil. It has not been observed in ionograms recorded at the neighbouring station São Luis. Model calculations have shown that the F3 layer is most likely to form in summer at Fortaleza due to a combination of the neutral wind and the $\mathbf{E} \times \mathbf{B}$ drift acting to raise the plasma. At the location of São Luis, almost on the geomagnetic equator, the neutral wind has a smaller vertical component so the F3 layer does not form.
\end{abstract}

\section{Introduction}

At the magnetic equator the geomagnetic field is horizontal which, together with the daytime east-west electric field, produces a vertical $\mathbf{E} \times \mathbf{B}$ drift which forces plasma upward at latitudes close to the equator. At higher altitudes the plasma then diffuses downward along the geomagnetic field lines due to gravity and pressure gradients; this causes crests in the electron density to develop at around $\pm 16^{\circ}$ latitude and causes a plasma trough to form at the equator, the equatorial anomaly. For reviews of experimental and modelling work on the equatorial anomaly see Rajaram (1977), Moffett (1979), Anderson (1981), Walker (1981) and Bailey et al. (1996). Recent modelling work by Balan and Bailey (1995), Bailey and Balan (1996a) and Balan and Bailey (1996) studied the plasma fountain and the equatorial anomaly in the ionosphere over Jicamarca

\footnotetext{
* is now at British Antarctic Survey, NERC, Madingley Road, Cambridge, CB3 0ET, UK.

Correspondence to: B. Jenkins
}

under equinoctial conditions for moderate solar activity. The affect of the neutral wind and the $\mathbf{E} \times \mathbf{B}$ drift was investigated, and these studies showed the possibility of an additional layer in the $\mathrm{F}$ region at equatorial latitudes between 500 and $700 \mathrm{~km}$ altitude. In these papers this layer was called the $\mathrm{G}$ layer. However, recent studies have shown that the layer arises from the dynamics of the F layer at low latitudes. To be consistent with the well-established nomenclature of using capital letters to denote different regions of the ionosphere, e.g. D, E, and $\mathrm{F}$, and the region letter followed by a number to denote distinct layers within the region, e.g. F1 and F2, the layer has been renamed the F3 layer by Bailey et al. (1996).

The formation of the F3 layer is described in terms of the plasma fountain by Balan and Bailey (1995). An upward $\mathbf{E} \times \mathbf{B}$ drift causes the fountain, which raises the plasma to the topside ionosphere, so that an F3 layer may form at latitudes close to the equator. A transequatorial neutral wind causes the plasma fountain to become asymmetric (Rishbeth, 1972; Balan et al. 1996a; Titheridge, 1996) so the location of the F3 layer may change. Once formed the F3 layer can persist throughout the day. The peak density of the F3 layer may be greater than the peak density of the F2 layer for a short period of time before local noon. The strength of the F3 layer is strongly dependent upon the upward motion of the plasma. The formation and development of the F3 layer depend upon factors that change the amount of upward flux, such as the $\mathbf{E} \times \mathbf{B}$ drift, neutral wind, season and solar activity. Experimental evidence for the F3 layer has been observed in ionograms recorded at Fortaleza and these were presented by Balan and Bailey (1995) and Balan et al. (1996b). Indirect evidence of the presence of an F3 layer was also discussed by Balan and Bailey (1995). These studies were mainly concerned with the affect of the neutral wind on the plasma fountain at three locations to try and determine the relative importance of the declination angle and the displacement of the geographic and magnetic equators in modulating the plasma fountain. The studies were again carried out under equinoctial conditions but for high solar activity. 
In this paper further observational evidence of the $\mathrm{F} 3$ layer recorded in ionograms at Fortaleza is presented together with results from model calculations for summer and winter during solar minimum. The model calculations are used to explain the formation of the layer and to predict the conditions most likely to lead to the development of an F3 layer. The present results demonstrate the role of a trans-equatorial neutral wind as a necessary condition for the formation of the F3 layer during solar minimum.

\section{Observations of an F3 layer}

Ionograms recorded at Fortaleza (geographic latitude $4^{\circ} \mathrm{S}$, geographic longitude $38^{\circ} \mathrm{W}$; dip angle $-9^{\circ}$ ) are presented in Figs. 1 and 2. The ionogram (a) shown in Fig. 1 was taken at 1120 LT on 23 December 1994 and it shows well-formed F1, F2 and F3 layers. The F3 layer occurs at a virtual height of $560 \mathrm{~km}$. The ionograms were recorded every 5 minutes and the F3 layer was observed around the same virtual height for a few hours from 0930 until just before local noon. Its non appearance after midday is demonstrated by ionogram (b) of Fig. 1 which was taken at $1330 \mathrm{LT}$. This is in agreement with the findings of Balan and Bailey (1995), who calculated that the F3 layer would only be of greater magnitude than the F2 layer (and hence observable in the ionogram) for a short period of time before local noon. Near simultaneous observations at the neighbouring station São Luis (geographic latitude $2.3^{\circ} \mathrm{S}$, geographic longitude $44^{\circ} \mathrm{W}$; dip angle $-0.5^{\circ}$ ), located very close to the magnetic equator, did not detect any F3 layer (see ionogram (c) in Fig. 1). Figure 2 shows an ionogram, (a), recorded over Fortaleza at 1120 LT on 21 May 1995 and an ionogram, (b), recorded over São Luis at 1100 LT on the same day. Presence of an F3 layer, though weak in magnitude, is evident over Fortaleza but not over São Luis. Both these sets of ionograms (Figs. 1 and 2) were recorded during solar minimum and they represent summer (December) and winter (May) conditions. From a preliminary examination of the data a definite seasonal pattern of F3 layer occurrence could not be established. However, there is an indication that, during solar minimum, the F3 layer persists less in equinox than in summer. Also, a preliminary search of ionograms over São Luis shows no presence of an F3 layer under magnetically quiet conditions. However, a few cases have been observed during magnetically disturbed conditions, a detailed study of these cases is being pursued.

We point out that the F3 layer cusp that characterises a stratification of the F-region cannot be the signature of a propagating disturbance such as that caused by a gravity wave for the following reasons:

1. The F3 layer cusp always occurs at the high frequency end of the trace and does not propagate downward in successive ionograms as would be expected of the downward phase propagation characteristics usually presented by a gravity wave (see for example, Abdu et al., 1982).
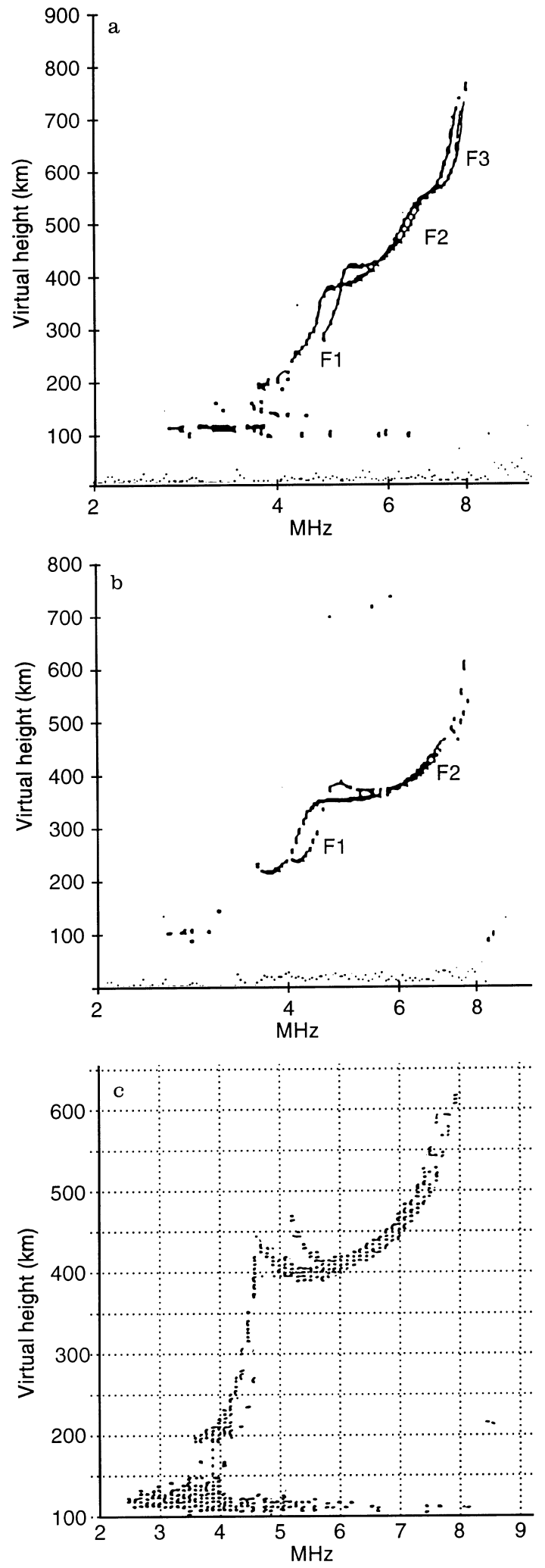

Fig. 1. Ionograms recorded on December 23 1994: (a) 1120 LT at Fortaleza; (b) 1330 LT at Fortaleza; (c) 1115 LT at São Luis

2. The phenomenon only occurs during a few hours before local noon, exactly at the local time interval when the equatorial zonal electric field shows a daytime maximum (see, for example, Fejer et al., 1995). 

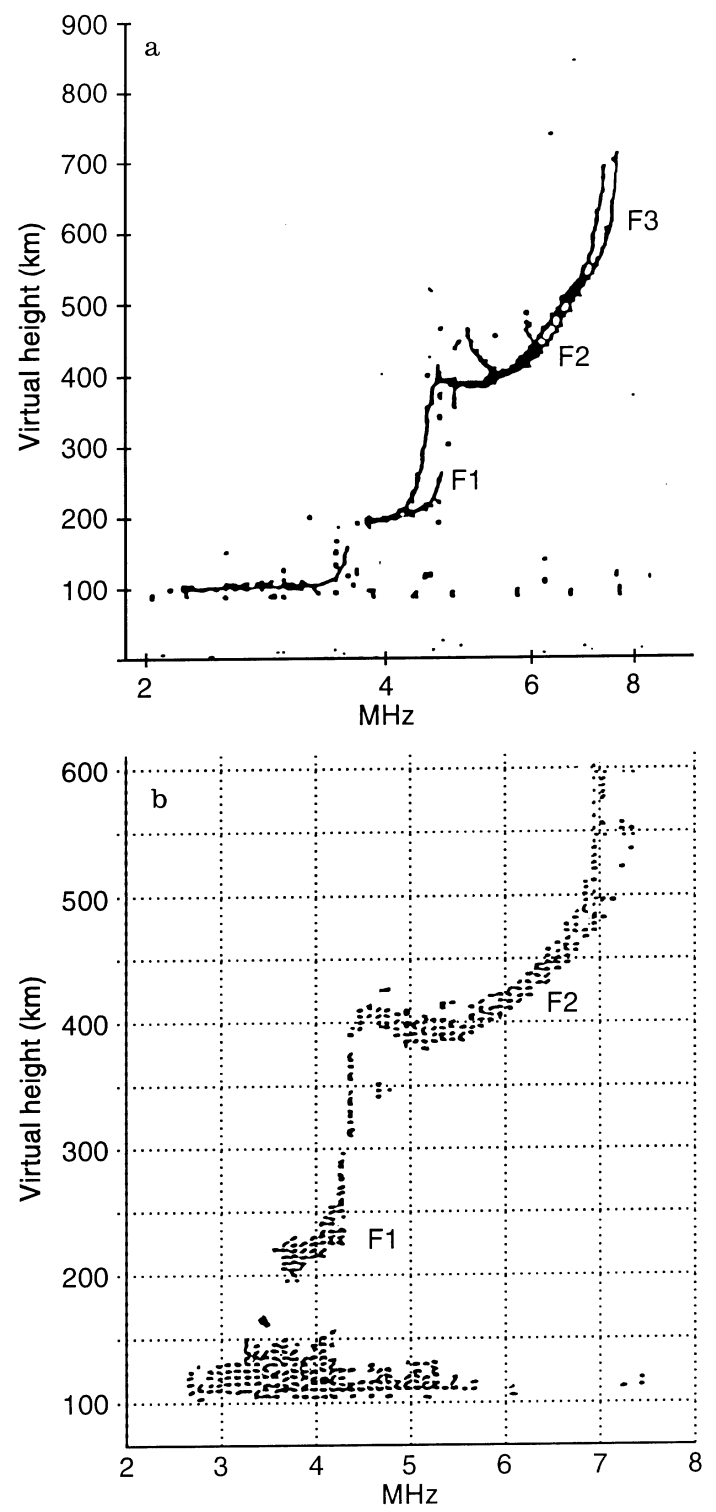

Fig. 2. Ionogram recorded on May 21 1995: (a) 1120 LT at Fortaleza; (b) 1100 LT at São Luis

3. The two traces, ordinary and extra-ordinary (Corresponding to the two magneto-ionic components of the probing radio wave) always present similar degrees of stratification which need not be the case if they (the cusps) were produced by a propagating gravity wave; the reflection points of the two radio waves are known to be meridionally separated. Of course, a zonally propagating disturbance could possibly cause similar cusps in the two traces, but such a hypothesis will not stand the test of point 1 above.

4. No periodicity in the intensity of the cusp was observed. This is an expected characteristic of a wave disturbance.

\section{Model description}

Model calculations have been carried out appropriate to Fortaleza and São Luis to try to understand the processes that cause the F3 layer to form and to determine under what conditions the peak density is most likely to be greater than the peak density of the F2 layer.

This investigation is carried out using the Sheffield University plasmasphere-ionosphere model, SUPIM (Bailey et al., 1993; Bailey and Balan 1996b). SUPIM solves the coupled time-dependent equations of continuity, momentum and energy balance for the electrons and the $\mathrm{O}^{+}, \mathrm{H}^{+}, \mathrm{He}^{+}, \mathrm{N}_{2}^{+}, \mathrm{O}_{2}^{+}$and $\mathrm{NO}^{+}$ions. The outputs are the densities, plasma fluxes and temperatures of the electrons and ions. The neutral atmosphere temperatures and densities are calculated from MSIS-86 (Hedin, 1987) and the neutral wind from HWM90 (Hedin et al., 1991). The model includes the solar EUV fluxes from the EUV94 model, an upgraded version of EUV91 (Tobiska, 1991). For the present study, the equations are solved along 91 closed magnetic field lines between base altitudes of about $130 \mathrm{~km}$ in conjugate hemispheres and parameter values are output for the final 24 hours of model calculations between $\pm 30^{\circ}$ latitude and $200-2000 \mathrm{~km}$ altitude.

There is some concern that the winds predicted by HWM90 for low latitudes are not very accurate, see for example $\mathrm{Su}$ et al. (1995). A detailed simulation of data is not being attempted, only a general seasonal investigation, so HWM90 was used, particularly as no measured wind data was available as an alternative (Stening, 1992).

The vertical $\mathbf{E} \times \mathbf{B}$ drift velocity used in the present study is based upon measurements made at Jicamarca and the results of previous studies. It varies along the magnetic field lines in accordance with the field line geometry (Bailey et al., 1993) and is assumed to be longitude independent (Fejer et al., 1995). The drift velocity at the equator is taken from the average drift pattern constructed by Fejer et al. (1991) from measurements made at Jicamarca; this is subject to an altitude dependence based on the modelling work of $\mathrm{Su}$ et al. (1995), the observations of Pingree and Fejer (1987), and the theoretical work of Murphy and Heelis (1986). In the present investigation the Jicamarca drift pattern is used for field lines with apex altitude less than $450 \mathrm{~km}$, the drift velocity is assumed to be zero for field lines with apex altitude greater than $3000 \mathrm{~km}$, and a linear interpolation is used for intermediate field lines. The zonal component of the $\mathbf{E} \times \mathbf{B}$ drift velocity is not included as this is thought to have only a negligible effect on the plasma concentrations (Anderson, 1981). Temporal plots of the $\mathbf{E} \times \mathbf{B}$ drift velocities used in the model calculations are shown in Fig. 3. The drifts for winter (May-August), summer (November-February) and equinox (March-April and September-October) for low solar activity are shown. During the morning the drift increases steadily upward and peaks just before noon; for each season the value reached before noon is a maximum at solar minimum. 


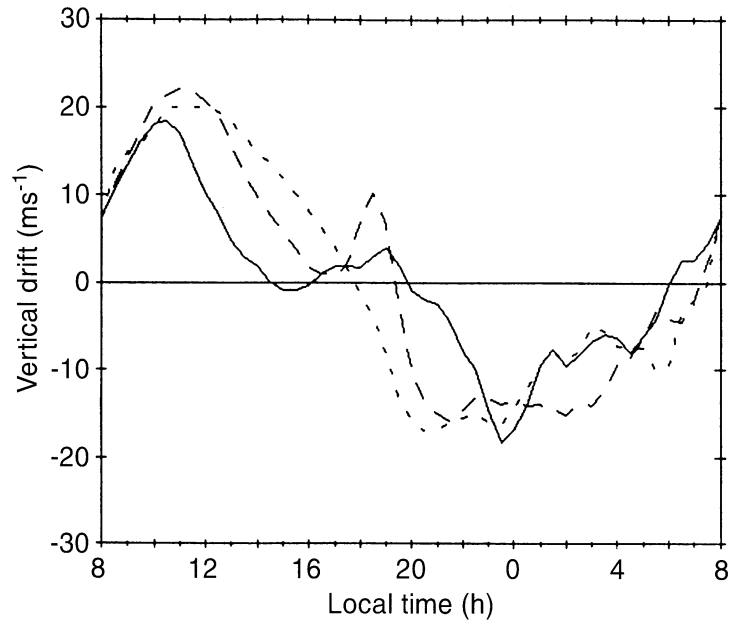

Fig. 3. F-region vertical $\mathbf{E} \times \mathbf{B}$ drift velocity patterns used in the model at the magnetic equator during solar minimum: summer, $\cdots \cdots \cdots$ winter and ---- equinox

\section{Model results}

Calculations have been carried out for winter, summer and equinox at Fortaleza and at São Luis. Solar minimum conditions appropriate to the observational data presented in Figs. 1 and 2 were used. Calculations have been carried out with and without the neutral air wind. At the solstices, the neutral winds generally blow from the summer to the winter hemisphere and are largest at solar minimum. The winds are smaller at equinox when the thermosphere is more symmetric than at the solstices.

\subsection{Summer hemisphere}

In summer at solar minimum the $\mathbf{E} \times \mathbf{B}$ drift is large during the morning which raises the F-region plasma to form the plasma fountain and equatorial anomaly. The meridional neutral wind in this case blows from the southern (summer) hemisphere to the northern (winter) hemisphere and causes the distribution of plasma to become asymmetric. At the magnetic latitude of Fortaleza there is a strong equatorward component along the field line during the day raising the plasma still further. At São Luis, situated almost on the magnetic equator, the field lines are almost horizontal so the neutral wind cannot raise the plasma. This can be seen in Fig. 4, which shows the plasma fluxes at 1130 LT (1430 UT) as a function of latitude and altitude. At the magnetic latitude of Fortaleza there is a very strong upward transfer of plasma, this is much weaker at the magnetic latitude of São Luis. This means that during the morning the upward flux at Fortaleza causes an F3 layer to form. At São Luis the upward transport of plasma is much less than at Fortaleza and although an F3 layer does form it is much weaker than the one predicted for Fortaleza and has a peak value comparable to that of the F2 layer. This would make it difficult to observe the F3 layer in an ionogram. Altitude profiles

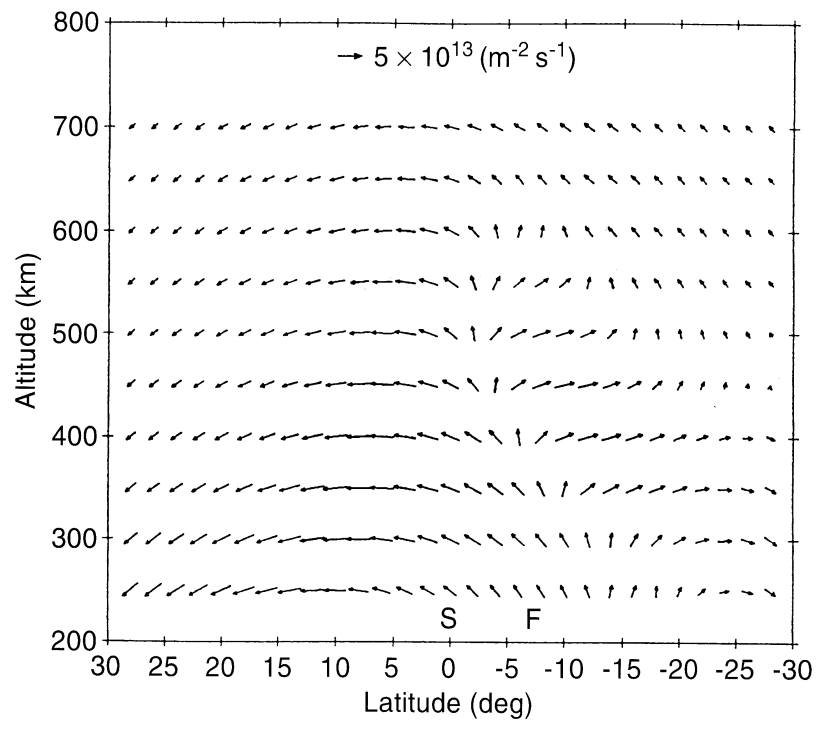

Fig. 4. Modelled vector plasma fluxes for solar minimum summer at $1130 \mathrm{LT}$

of electron density at $1130 \mathrm{LT}$ at the magnetic latitudes of Fortaleza and São Luis are shown in Fig. 5a. At this time the F3 layer is stronger than the F2 layer at Fortaleza due to the combination of drift and wind. At São Luis the F2 and F3 layer peaks are of comparable magnitude. Figure $5 \mathrm{~b}$ shows the profiles at $1330 \mathrm{LT}$. By this time the F3 layer is much weaker than the F2 layer at São Luis, and at Fortaleza, the two peaks have merged together to form a single broad peak. This evolution is demonstrated in Fig. 1b which shows only the F2 trace in the ionogram at $1330 \mathrm{LT}$. Model calculations in which the neutral wind is set to zero show that the plasma fountain remains symmetric and that there is a much smaller transfer of plasma upward and an F3 layer does not form at either of the magnetic latitudes of Fortaleza or São Luis. The electron density profiles at Fortaleza in the absence of the neutral air wind are shown in Fig. 5c for 1130 and 1330 LT. Figures $6 \mathrm{a}$ and $6 \mathrm{~b}$ show the latitudinal extent of the F3 and F2 layers in summer at solar minimum at $1130 \mathrm{LT}$. The F3 layer is present between latitudes $-8^{\circ}$ to $+6^{\circ}$ and is of greater magnitude than the F2 layer between $-1^{\circ}$ and $-8^{\circ}$.

In general, the model predicts that an F3 layer will form in the summer hemisphere out to about $-8^{\circ}$ magnetic latitude, but it is dependent on both the neutral wind and the $\mathbf{E} \times \mathbf{B}$ drift. Halving the morning $\mathbf{E} \times \mathbf{B}$ drift or halving the value of the neutral wind will cause the F3 layer to disappear. The same behaviour is observed at solar maximum.

\subsection{Winter hemisphere}

In winter solar minimum the $\mathbf{E} \times \mathbf{B}$ drift is upward during the morning and is larger than in summer. However, it is insufficient magnitude to form an F3 layer. In winter (in the southern hemisphere) the neutral 


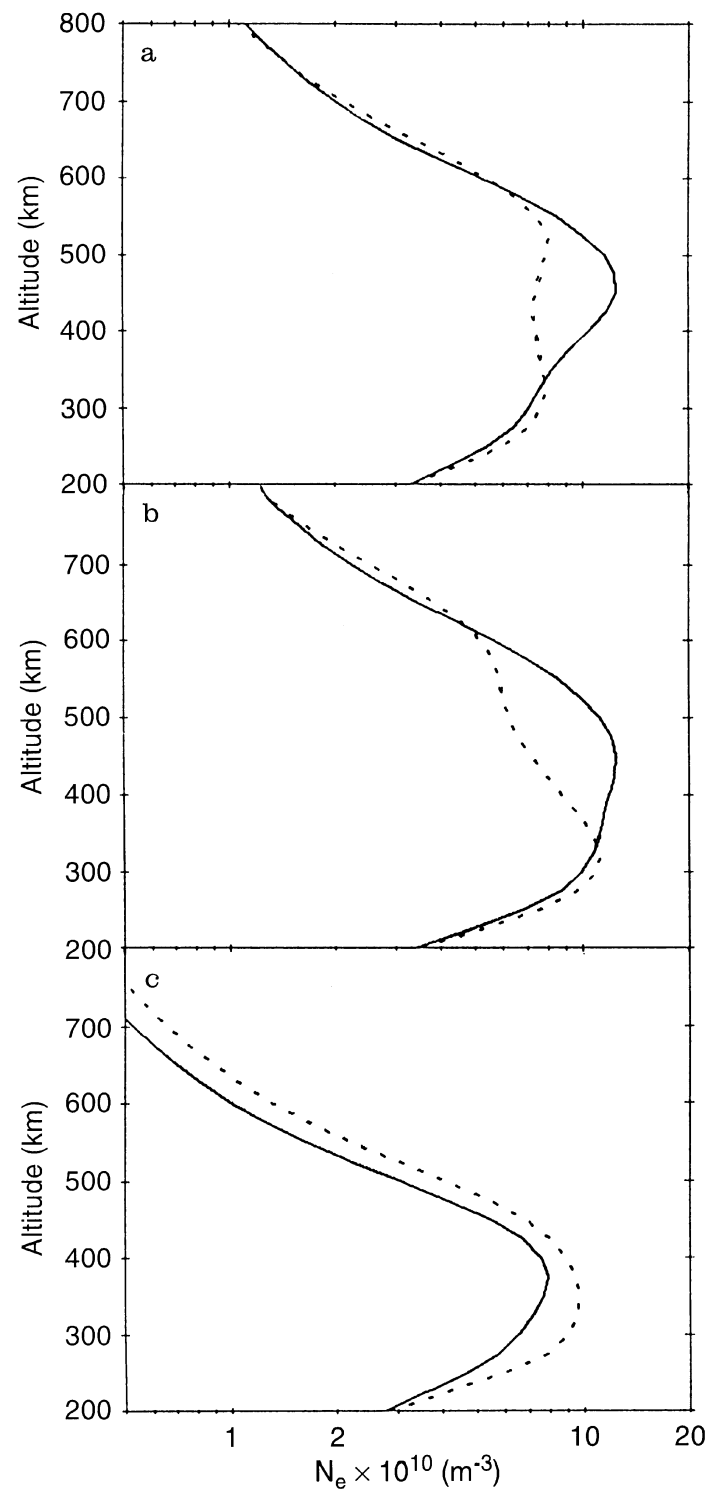

Fig. 5. Electron density profiles modelled for summer at solar minimum:

a with drift and wind: - Fortaleza at 1130 LT, $\cdots \cdots \cdots$ São Luis at $1130 \mathrm{LT}$;

b with drift and wind: $\longrightarrow$ Fortaleza at 1330 LT, $\cdots \cdots$ São Luis at $1330 \mathrm{LT}$;

c with drift but no wind: - Fortaleza at $1130 \mathrm{LT}, \ldots \ldots \ldots$ Fortaleza at $1330 \mathrm{LT}$

wind blows in the opposite sense to the summer months. This means that at the location of Fortaleza the wind generally acts so as to move plasma down the field line and we do not expect an F3 layer to form. At the magnetic latitude of São Luis the neutral wind has a smaller component and the model predicts an F3 layer will form but that it will be of lower magnitude than the F2 layer. An examination of the data shows that the F3 layer can in fact be observed also in a winter month over Fortaleza. An example was shown in Fig. 2 for 21 May 1995 at 1120 LT. However, the magnitude of the F3 layer is smaller than that of the summer events (an example of which was presented for 23 December 1994

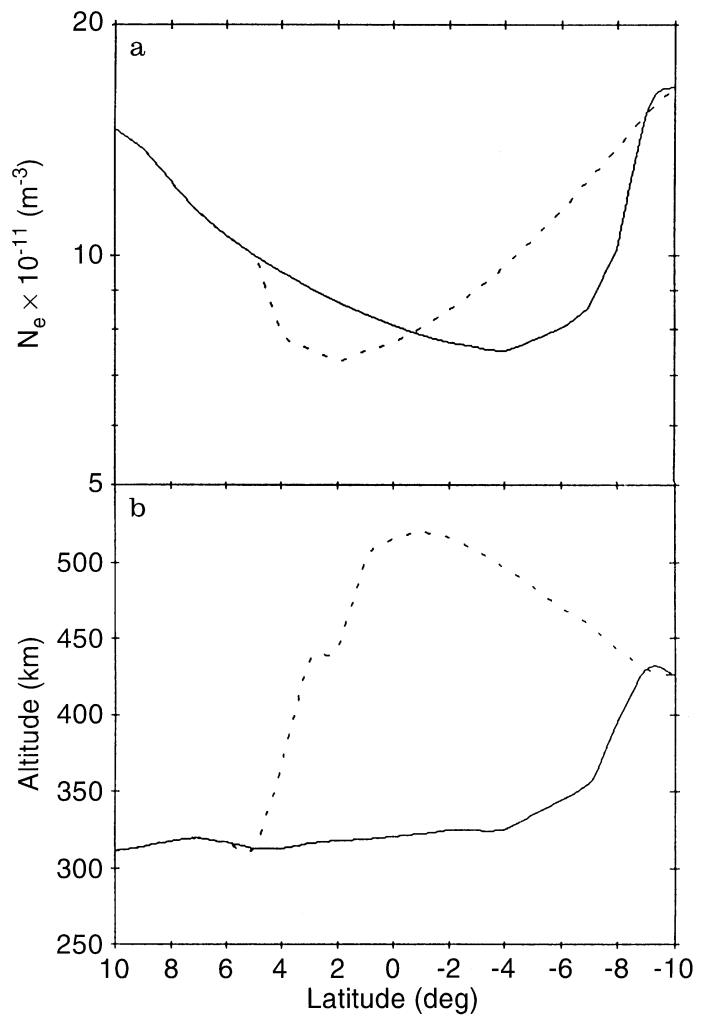

Fig. 6. Peak values of the F2 and F3 layers as a function of latitude at $1130 \mathrm{LT}$ in summer at solar minimum; $\mathbf{a}-\mathrm{NmF} 2, \ldots \ldots \ldots$. $\mathrm{NmF} 3 ; \mathbf{b}-\mathrm{hmF} 2, \cdots \ldots \cdot \mathrm{hmF} 3$

in Fig. 1). If in the model calculations the equatorward component of the neutral wind is halved during the morning, then in this case the model does predict the presence of an F3 layer at the location of Fortaleza. This can be verified by reference to Fig. 7 , which is an altitude plot of electron density at 1130 LT. The full line is for Fortaleza, the dotted line is for São Luis. This is in agreement with the observations shown in Fig. 2. The observation of the F3 layer shown in Fig. 2 corresponds to one of the quietest days of the month; the Ap value for 21 May being 5. This would suggest that the

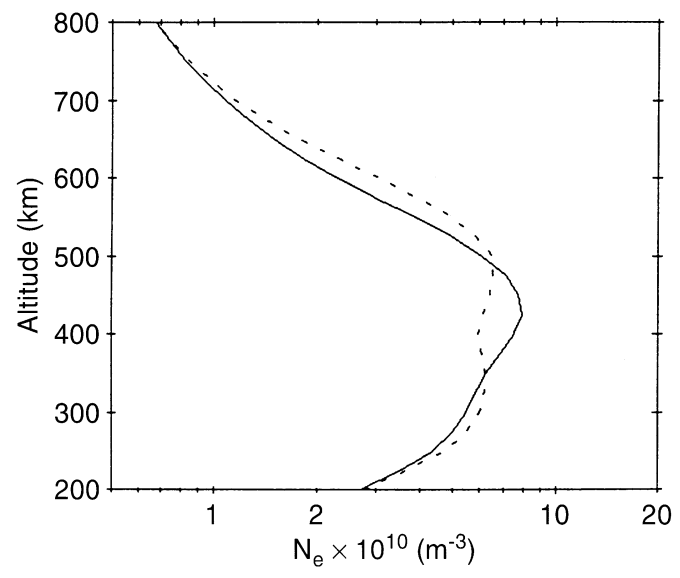

Fig. 7. Altitude profiles of electron density modelled for winter at 1130 LT: — Fortaleza; ........ São Luis 
HWM90 meridional wind for winter morning conditions of the Brazilian low latitude region is not sufficiently realistic under quiet conditions. Some cases of simultaneous F3 layer occurrences at Fortaleza and São Luis during winter months have been observed under magnetically disturbed conditions. A detailed study of such events is to be carried out at a later date. Under solar maximum conditions the model, using HWM90 winds, predicts that no F3 layer will form at either Fortaleza or São Luis.

\subsection{Equinox}

Results for equinox for moderate solar activity have been described by Balan and Bailey (1995) and for high solar activity by Balan et al. (1996b). At equinox during solar minimum the morning drifts are slightly stronger than at the solstices but the neutral wind is smaller in magnitude. This means that, under quiet conditions, an F3 layer forms around the magnetic equator only and not at the location of Fortaleza; the peak value is usually smaller than the F2 layer peak and it is therefore not observed in the ionograms. At solar maximum there is sufficient plasma for the F3 layer to be of greater magnitude than the F2 layer as described by Balan et al. (1996b). Both the F3 and F2 layers are predicted to be well-defined during equinox but at solar minimum the F3 layer is present only within $\pm 4^{\circ}$ of the magnetic equator. This means it may be visible at São Luis but again, it is predicted to be less than or only of slightly greater density than the F2 layer and may not be easily observed.

\section{Summary}

SUPIM has been used to study the equatorial ionosphere above Fortaleza and São Luis in summer, winter and equinox at solar minimum. Ionograms recorded at Fortaleza in summer and winter show clear evidence for the development of an F3 layer.

In summer at Fortaleza (December 23, 1994) the model predicts the formation of an F3 layer due to a combination of $\mathbf{E} \times \mathbf{B}$ drifts and neutral air winds. The large morning drift around the equator at solar minimum raises the plasma to higher altitudes and the strong wind blowing from the summer hemisphere to the winter hemisphere also acts to raise the plasma at the magnetic latitude of Fortaleza $\left(7^{\circ} \mathrm{S}\right)$. This lifting of the plasma produces an F3 layer which has a peak value greater than the peak value of the F2 layer just before local noon. At São Luis, which lies almost on the magnetic equator, the wind has a smaller vertical component than at Fortaleza and consequently the F3 layer is weaker. When either the drift or the wind is reduced the F3 layer fails to form.

In winter there is a large upward $\mathbf{E} \times \mathbf{B}$ drift during the morning but the winds are opposite in direction to the winds in the summer and act to lower the plasma, hence the model predicts that no F3 layer should form in the southern hemisphere. However, when the magnitude of the HWM90 meridional wind was reduced in the morning hours the F3 layer formation was indeed predicted for the location of Fortaleza. This was observed in the ionograms though with reduced magnitude compared to the summer event. The F3 layer formation predicted under similar conditions for São Luis was not significant enough to be detected in the ionogram over that location.

At equinox the model predicts that the F3 layer will be of lower magnitude than the F2 layer except at solar maximum when at latitudes close to the magnetic equator $\mathrm{NmF} 3$ may exceed $\mathrm{NmF}$.

Acknowledgements. This work was supported by PPARC, UK under grants: GR/K06112 and GR/L20238. N.B. was supported by fellowships from the Institute of Space and Astronautical Science (Japan) and the Radio Atmospheric Science Center (Japan). The ionograms over Fortaleza were acquired using a CADI (Canadian Advanced Digital Ionosonde) instrument in collaboration with John MacDougall of the University of Western Ontario, Canada.

Topical Editor D. Alcaydé thanks H. Rishbeth and K. I. Oyama for their help in evaluating this paper.

\section{References}

Abdu, M. A., I. S. Batista, I. J. Kantour and J. H. A. Sobral, Gravity wave induced ionization layers in the night F-region over Cachoeira Paulista $\left(22^{\circ} \mathrm{S}, 45^{\circ} \mathrm{W}\right)$, J. Atmos. Terr. Phys., 44, 759, 1982.

Anderson, D. A., Modelling the ambient, low latitude $\mathrm{F}$ region ionosphere - A review, J. Atmos. Terr. Phys., 43, 753, 1981.

Bailey, G. J. and N. Balan, Some modelling studies of the equatorial ionosphere using the Sheffield University Plasmasphere ionosphere model, Adv. Spac. Res., 18(6), 59, 1996a.

Bailey, G. J. and N. Balan, A low latitude ionosphere-plasmasphere model, in STEP Handbook on Ionospheric Models, Ed. R. W. Schunk, Utah State University, 173, 1996b.

Bailey, G. J., N. Balan and Y. Z. Su, The Sheffield University ionosphere plasmasphere model - A review, J. Atmos. Terr. Phys., in press, 1996.

Bailey, G. J., R. Sellek and Y. Rippeth, A modelling study of the equatorial topside ionosphere, Ann. Geophys., 11, 263, 1993.

Balan, N. and G. J. Bailey, Equatorial plasma fountain and its effects: possibility of an additional layer, J. Geophys. Res., 100, 21421, 1995

Balan, N. and G. J. Bailey, Modelling studies of equatorial plasma fountain and equatorial anomaly, Adv. Space. Res., 18(3), 107, 1996.

Balan, N., G. J. Bailey, K. S. V. Subbarao, M. A. Abdu and P. B. Rao, Model comparisons of equatorial plasma fountain and equatorial anomaly at three locations, Adv. Space. Res., 18(6), 69, 1996a.

Balan, N., G. J. Bailey, M. A. Abdu, K. I. Oyama, P. G. Richards, J. MacDougal and I. S. Batista, Equatorial plasma fountain and its effects over three locations: Evidence for an additional layer, the F3 layer, J. Geophys. Res., in press, 1996b.

Fejer, B. G., E. R. de Paula, S. A. Gonzales and R. F. Woodman, Average vertical and zonal F region plasma drifts over Jicamarca, J. Geophys. Res., 96, 13901, 1991.

Fejer, B. G., E. R. de Paula, R. A. Heelis and W. B. Hanson, Global equatorial ionospheric vertical plasma drifts measured by the AE-E satellite, J. Geophys. Res., 100, 5769, 1995.

Hedin, A. E., MSIS-86 thermospheric model, J. Geophys. Res., 92, 4649, 1987.

Hedin, A. E., M. A. Biondi, R. G. Burnside, G. Hernandez, R. M. Johnson, T. L. Killeen, C. Mazaudier, J. W. Meriwether, J. E. 
Salah, R. J. Sica, R. W. Smith, N. W. Spencer, V. B. Wickwar and T. S. Virdi, Revised global model of thermosphere winds using satellite and ground-based observations, J. Geophys. Res., 96, 7657, 1991.

Moffett, R. J., The equatorial anomaly in the electron distribution of the terrestrial F region, Fund. Cosmic Phys., 4, 313, 1979.

Murphy, J. A. and R. A. Heelis, Implications of the relationship between the electromagnetic drift components at mid- and lowlatitudes, Planet. Space Sci., 34, 645, 1986.

Pingree, J. E. and B. G. Fejer, On the height variation of the equatorial F region vertical plasma drifts J. Geophys. Res., 92, 4763, 1987.

Rajaram, G., Structure of the equatorial $\mathrm{F}$ region, topside and bottomside - A review, J. Atmos. Terr. Phys., 39, 1125, 1977.
Rishbeth, H., Thermospheric winds and the F region: A review, $J$. Atmos. Terr. Phys., 43, 1, 1972.

Stening, R. J., Modelling the low latitude F region, J. Atmos. Terr. Phys., 57, 433, 1992.

Su, Y. Z., K. I. Oyama, G. J. Bailey, T. Takahashi and S. Watanabe, Comparison of satellite electron density and temperature measurements at low latitudes with a plasmasphereionosphere model, J. Geophys. Res., 100, 14591, 1995.

Titheridge, J. E., Winds in the ionosphere - a review, J. Atmos. Terr. Phys., in press, 1996.

Tobiska, W. K., Revised solar extreme ultraviolet flux model, $J$. Atmos. Terr. Phys., 53, 1005, 1991.

Walker G. O., Longitudinal structure of the $\mathrm{F}$ region equatorial anomaly-A review, J. Atmos. Terr. Phys., 43, 763, 1981. 